\title{
Continuous-flow precipitation of hydroxyapatite in ultrasonic microsystems
}

\author{
Filipa Castro $^{\mathrm{a}, *}$, Simon Kuhn $^{\mathrm{b}}$, Klavs Jensen ${ }^{\mathrm{c}}$, António Ferreira ${ }^{\mathrm{a}}$, Fernando Rocha ${ }^{\mathrm{d}}$, António Vicente ${ }^{\mathrm{a}}$, \\ José António Teixeira ${ }^{a}$ \\ ${ }^{a}$ IBB - Institute for Biotechnology and Bioengineering, Centre for Biological Engineering, University of Minho, Campus de Gualtar, 4710-057 Braga, Portugal \\ ${ }^{\mathrm{b}}$ Department of Chemical Engineering, Massachusetts Institute of Technology, 77 Massachusetts Avenue, Building 66-240, Cambridge, MA 02139-4307, United States \\ ${ }^{\mathrm{c}}$ Department of Chemical Engineering, Massachusetts Institute of Technology, 77 Massachusetts Avenue, Building 66-350, Cambridge, MA 02139-4307, United States \\ ${ }^{\mathrm{d}}$ LEPAE - Laboratory for Process, Environmental and Energy Engineering, Faculty of Engineering of the University of Porto, Rua Roberto Frias, s/n, 4200-465 Porto, Portugal
}

\section{H I G H L I G H T S}

- Continuous-flow precipitation of HAp was studied in two ultrasonic microreactors.

- A tubular reactor and a novel Teflon reactor were investigated.

- Laminar flow and segmented flow were both evaluated.

- Both reactors produce HAp under near-physiological conditions of temperature and $\mathrm{pH}$.

- HAp particles with improved properties were obtained in a short time.

\section{A R T I C L E I N F O}

\section{Article history:}

Received 13 March 2012

Received in revised form 22 October 2012

Accepted 2 November 2012

Available online 10 November 2012

\section{Keywords:}

Microfluidics

Ultrasound

Nanoparticles

Hydroxyapatite

Aggregation

\begin{abstract}
A B S T R A C T
This paper describes the continuous-flow precipitation of hydroxyapatite $\mathrm{Ca}_{5}\left(\mathrm{PO}_{4}\right)_{3} \mathrm{OH}(\mathrm{HAp})$ in two ultrasonic microreactors using diluted aqueous solutions of calcium and phosphate at $37^{\circ} \mathrm{C}$. Precipitation of HAp was first carried out in a tubular microreactor immersed in an ultrasonic bath, where single-phase (laminar) flow and segmented gas-liquid flow were both evaluated. The single-phase flow study was then conducted in a novel microfluidic device developed at MIT. It consists of a Teflon stack microreactor with an integrated piezoelectric element (Teflon microreactor), thereby allowing the direct transmission of ultrasound to the reactor. Both microsystems produce single-phased calcium-deficient carbonated HAp under near-physiological conditions of temperature and $\mathrm{pH}$. In addition, particle aggregation and primary particle size were significantly reduced in the segmented-flow tubular microreactor and in the Teflon microreactor. The as-prepared particles mostly consisted of rod-like shape nanoparticles with dimensions below $100 \mathrm{~nm}$ in length and around $20 \mathrm{~nm}$ in width. Further, the microreactors used yielded HAp particles with improved characteristics, namely higher crystallinity and less carbonate contamination, when compared to the HAp particles produced in a stirred tank batch reactor.
\end{abstract}

(ㄷ) 2012 Elsevier B.V. All rights reserved.

\section{Introduction}

The preparation and properties of nanoparticles have received considerable attention due to their wide range of applications in fields such as biomedicine, electronics and optics. But synthesis of nanoparticles with controlled size, shape and composition remains a challenge [1]. The current approach based on wet chemical synthesis in stirred tank yields particles with rather broad size distributions because of the low mixing efficiency and wide residence time distributions [2,3]. In order to overcome the limitations associated with this type of reactor, microfluidic devices have been studied. Their intrinsic small volume allows a reduction of energy

\footnotetext{
* Corresponding author. Tel.: +351253 604400; fax: +351 253678986 .

E-mail address: fcastro@deb.uminho.pt (F. Castro).
}

costs, reagent consumption and waste generated, as well as improved safety. Besides, their high surface to volume ratio, efficient heat and mass transfer characteristics, vastly improved fluid mixing, allowing a better control of the reaction steps that govern particle size distribution, i.e., nucleation and growth, and thereby improving the monodispersity of synthesized nanoparticles [48]. Moreover, microfluidic reactors have the ability to operate within continuous flow regimes, which besides being more productive and able to promote more homogeneous reaction conditions, yet permits the continuous variation of the chemical composition of the reaction medium $[6,8]$.

However, there are difficulties accompanying the handling of solids in microfluidics, such as transport behavior [4,6] and channel clogging [9]. Microreactors are usually characterized by geometries with a low Reynolds number. In such channels, laminar flow 
is dominant and is characterized by a parabolic velocity profile, leading to residence time distributions. In this context, it has been shown that segmented-flow microreactors can narrow the residence time distribution by carrying out reactions in segmented liquid slugs, gas-liquid segmented-flow reactors being particularly attractive due to the simple separation process of the gas from the liquid $[8,10,11]$. As to channel clogging, it can be caused by particle aggregation, which can significantly be reduced by the use of ultrasound. Cavitation breakups aggregates and shortens contact time between particles thus preventing formation of channel clogging [12].

Calcium phosphates, and especially hydroxyapatite $\mathrm{Ca}_{5}\left(\mathrm{PO}_{4}\right)_{3-}$ $\mathrm{OH}$ (HAp), are widely used as bone substitute material due to their similarity to the mineral portion of bone $[13,14]$. It is known that HAp particles characteristics, such as size, size distribution and chemical composition, are directly related to HAp properties such as biocompatibility, bioactivity and osteoconductivity $[15,16]$. HAp particles need to be produced with high specific surface area, narrow crystal size distribution and high purity, in order to improve bone-related cells growth around them.

In this work, two ultrasonic microsystems were used for the synthesis of HAp nanoparticles. Initially, continuous-flow precipitation of HAp was carried out in a tubular microreactor immersed in an ultrasonic bath, where single-phase (laminar) flow and gasliquid flow experiments were both performed. Continuous-flow precipitation of HAp in single-phase flow was then done in a novel microreactor made of Teflon plates, this time with the direct transmission of the ultrasound to the reactor through the integration of a piezoelectric actuator. Finally, the operating conditions, namely temperature, reactants concentration and mixing $\mathrm{Ca} / \mathrm{P}$ molar ratio, were defined in order to promote spontaneous formation of HAp under near-physiological conditions of temperature and $\mathrm{pH}$.

\section{Materials and methods}

\subsection{Experimental set-up}

Continuous-flow precipitation of HAp was first carried out in a tubular microreactor (Fig. 1) immersed in an ultrasonic bath, where single-phase (laminar) flow and gas-liquid flow studies were both performed. As it is exemplified in Fig. 1, the reactor is constituted by two main parts: a mixing chamber (Upchurch Scientific), with two different configurations depending on the flow type, a T-mixer for the single-phase flow (Fig. 1a) and a cross-mixer for the gas-liquid flow (Fig. 1b); and the tubular reactor (Teflon PFA, Upchurch Scientific) itself of $600 \mu \mathrm{L}$, with $1.02 \mathrm{~mm}$ in inner diameter and $1.59 \mathrm{~mm}$ in external diameter. The function of the first part of the reactor is to mix thoroughly the reactants and in the case of the gas-liquid flow study its function is also to segment the liquid mixture. The segmented gas is used to separate the liquid phase in small entities (Fig. 1b and c). In this way, the gas phase induces recirculation and enhances mixing within individual liquid slugs. The result is a narrow residence time distribution and reduced particle size polydispersity $[6,10]$. The reaction progresses in the second part of the reactor.

The reactants were fed into the set-up by means of a syringe pump (Harvard PHD 2000), where syringes were kept at $37^{\circ} \mathrm{C}$ through the use of thermal jackets (McMaster-Carr). With regard to the gas phase, the flow rate of nitrogen was adjusted by a mass flow controller (Sierra FlowBox). The microfluidic connections were provided by Teflon tubing (Upchurch Scientific) with $1.02 \mathrm{~mm}$ in inner diameter. The reactor was immersed in an ultrasonic bath (VWR model 50HT) to minimize the potential for clogging the reactor and the experiments were started with a temperature of $37^{\circ} \mathrm{C}$ in the ultrasonic bath.
Continuous-flow precipitation of HAp was also carried out in a Teflon microreactor with integrated piezoelectric actuator developed at MIT (Massachusetts Institute of Technology) (Fig. 2) [17]. The microreactor is made of Teflon (PTFE) plates, with an integrated piezoelectric element with a thickness of $1 \mathrm{~mm}$. The channel width is $600 \mu \mathrm{m}$ and the total volume is $1000 \mu \mathrm{L}$. The system has two inlets and one outlet. The microfluidic connections were provided by Teflon tubing (Upchurch Scientific) with $1.02 \mathrm{~mm}$ in inner diameter.

Reactants were mixed in a T-mixer (same mixing chamber used in the tubular microreactor for the single-phase study) (Fig. 3) before entering in the reactor, and thus only one inlet was used. As in the previous system, the reactants were fed into the reactor by means of a syringe pump (Harvard PHD 2000), where syringes were kept at $37^{\circ} \mathrm{C}$ through the use of thermal jackets (Upchurch Scientific).

\subsection{HAp precipitation}

HAp was synthesized by the mixing of a saturated calcium hydroxide (Sigma-Aldrich, 95\%) aqueous solution and an orthophosphoric acid (Mallinckrodt, 85\%) aqueous solution at $37^{\circ} \mathrm{C}$, with a mixing molar ratio $\mathrm{Ca} / \mathrm{P}=1.33$. This mixing molar ratio was defined in order to obtain the desired product, e.g. hydroxyapatite in conditions that promote the survival of cells, e.g. physiological conditions of $\mathrm{pH}$ and temperature. After several preliminary experiments we verified that with a mixing molar ratio $\mathrm{Ca} /$ $\mathrm{P}=1.33$ we could obtain the desired product at near physiological conditions of $\mathrm{pH}$ and temperature.

$0.5 \mathrm{~L}$ of both reactants was prepared with ultra-pure water (Milli $\mathrm{Q}$ water, resistivity of $18.2 \mathrm{M} \Omega / \mathrm{cm}$ at $25^{\circ} \mathrm{C}$ ) and their ionic force was adjusted by the addition of $6 \mathrm{~mL}$ of potassium chloride (Mallinckrodt, 99.8\%) $4 \mathrm{M}$ solution. To facilitate the dissolution of calcium hydroxide, the solution was agitated in a closed vessel for $24 \mathrm{~h}$ at $500 \mathrm{rpm}$ and at $25^{\circ} \mathrm{C}$, as its solubility decreases with temperature increase [18]. Then, both reactants were heated and kept at $37^{\circ} \mathrm{C}$. The operating conditions used are presented in Table 1.

Temperature (J-KEM Scientific) and $\mathrm{pH}$ (needle-like tip micro$\mathrm{pH}$ electrode, Thermo Fisher Scientific ORION) were measured at different time intervals at the outlet of the microsystems. The $\mathrm{pH}$ electrode was calibrated with two buffer solutions with $\mathrm{pH}=7.00$ and $\mathrm{pH}=10.00$ at $25^{\circ} \mathrm{C}$.

In a previous work [19], HAp precipitation was conducted in batch, in a $1 \mathrm{~L}$ stirred tank, under the same conditions of reagents concentration, mixing $\mathrm{Ca} / \mathrm{P}$ molar ratio and temperature. Carbonated HAp of B-type was synthesized, particles being collected after approximately $6 \mathrm{~h}$ at a final $\mathrm{pH}$ close to 7 . Results obtained in that work will be used for comparison.

\subsection{HAp characterization}

Samples were withdrawn at the outlet of the microreactors, centrifuged (at $1500 \mathrm{rpm}$ for $5 \mathrm{~min}$ ), washed twice with ultra pure water and conserved in ethanol (Koptec 200 proof pure), which stops the solid-liquid reaction [20]. For X-ray diffraction (XRD) (PanAlytical X'Pert PRO MPD), scanning electron microscopy (SEM) (FEI Quanta 400FEG ESEM/EDAX Genesis X4M, with an accelerating voltage of $20 \mathrm{kV}$ ) and transmission electron microscopy (TEM) (HR-(EF)TEM JEOL, 2200FS/EDS Oxford, INCA Energy TEM 250) studies, suspensions were dried at $T=80^{\circ} \mathrm{C}$ during $24 \mathrm{~h}$. For SEM analysis samples were covered by a $10 \mathrm{~nm}$ gold layer and for TEM analysis powders were suspended in ethanol and a small drop of the suspension was fixed on a support (Carbon film on 400 mesh, Monocomp). For Fourier transform infrared spectroscopy (FTIR) spectroscopy (Bruker Vertex 70 with MCT detector), a small drop of the suspension was put on a $1 \mathrm{~mm}$ thick $\mathrm{ZnSe}$ 

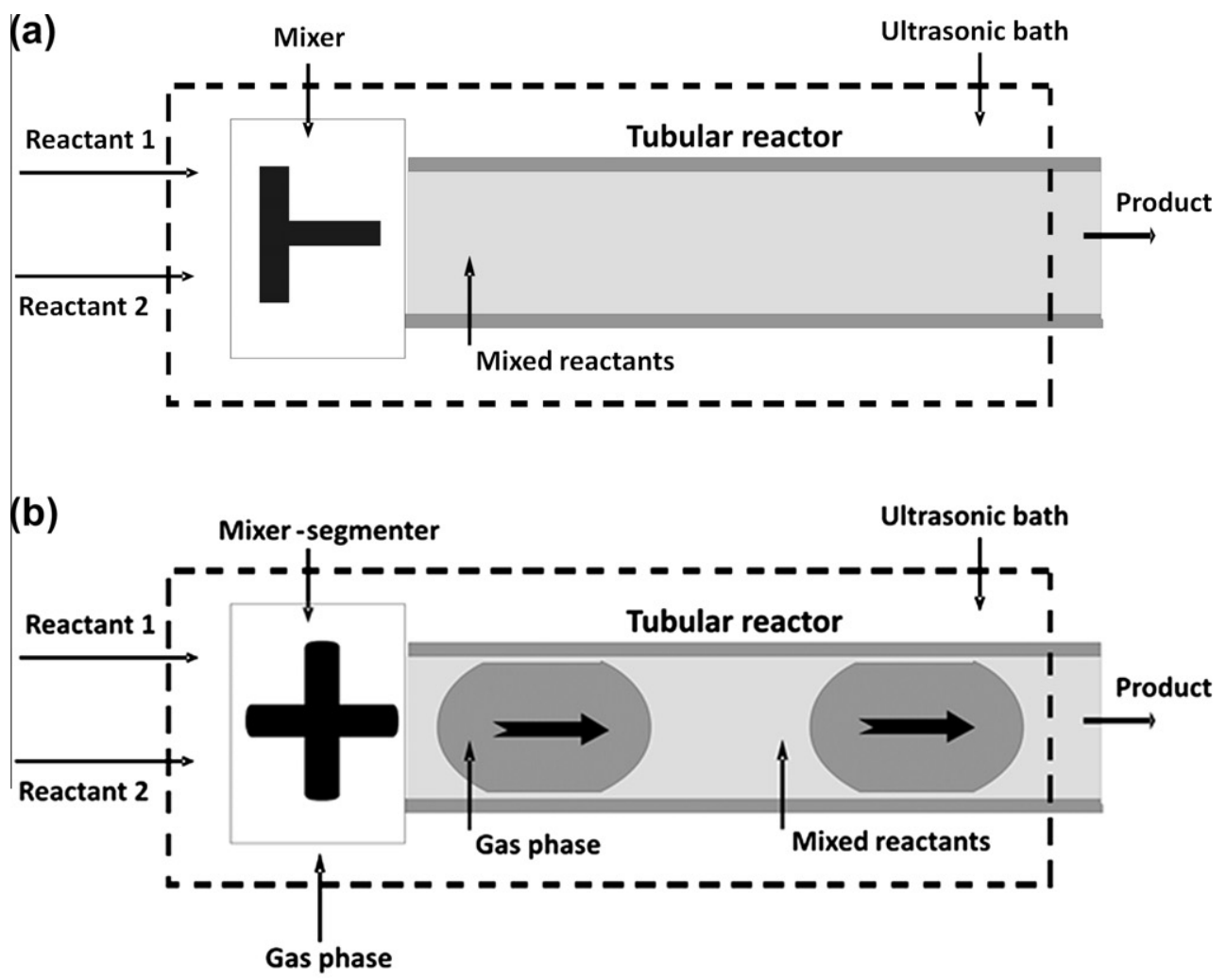

(c)

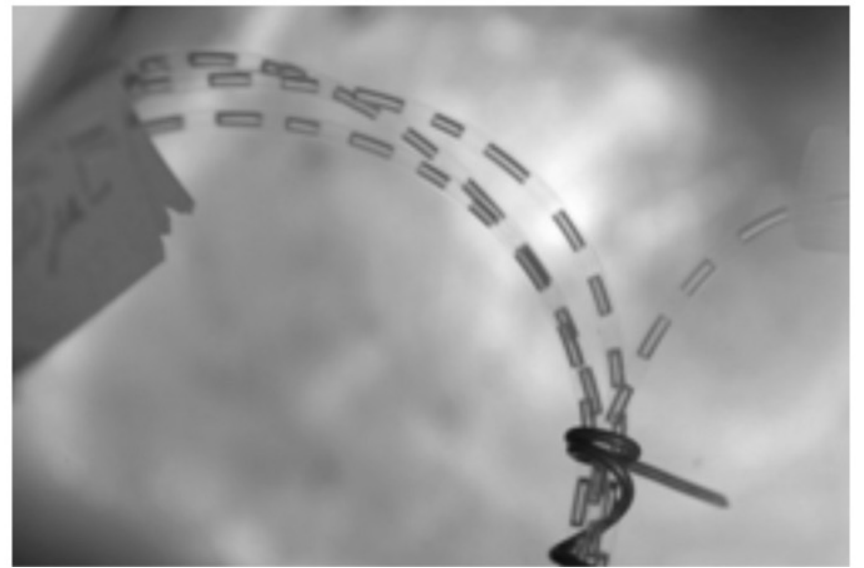

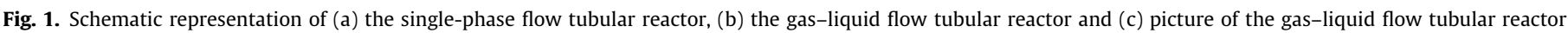
section.

support, dried $\left(80^{\circ} \mathrm{C}\right)$ to evaporate the ethanol and then analyzed. Finally, for particle size distribution analysis, suspensions were collected at the end of each experiment and directly analyzed using a Malvern Mastersizer 2000 apparatus.

\section{Results and discussion}

\subsection{Important parameters in the precipitation of HAp}

In this work, experiments were conducted under near-physiological conditions of temperature and $\mathrm{pH}$ (Table 2), which is particularly important when preparing HAp for medical purposes. Indeed, it is important to follow specific criteria for $\mathrm{pH}$ and temperature in order to promote more conductive conditions for the survival of bone-related cells [15]. Furthermore, from a thermodynamic point of view, these conditions favor the precipitation of HAp, since at body temperature and $\mathrm{pH}$ between 4 and 12, HAp is the most stable calcium phosphate salt [21]. However, considering the kinetics it does not imply that HAp is the only calcium phosphate to precipitate [22]. Therefore, diluted solutions were used (Table 1 ) to obtain low supersaturation and promote the formation of a homogeneous solution of hydroxide and calcium ions, so allowing a better control over the reaction conditions [19].

The continuous use of ultrasound could explain the increase in the temperature (Table 2). In fact, ultrasonic waves produce heat when passed through a substance due to the transfer of ultrasonic energy, making the maintenance of isothermal conditions difficult in the systems used. The problem is magnified in the Teflon microreactor, not only because of the higher power input but also because of the smaller area of irradiation [23] as compared to the tubular microreactor immersed in the ultrasonic bath. In the case 
stainless steel chuck

PTFE top layer

PTFE middle layer with microchannels

PTFE bottom layer

PTFE housing with piezoelectric actuator

PTFE insulation

stainless steel chuck

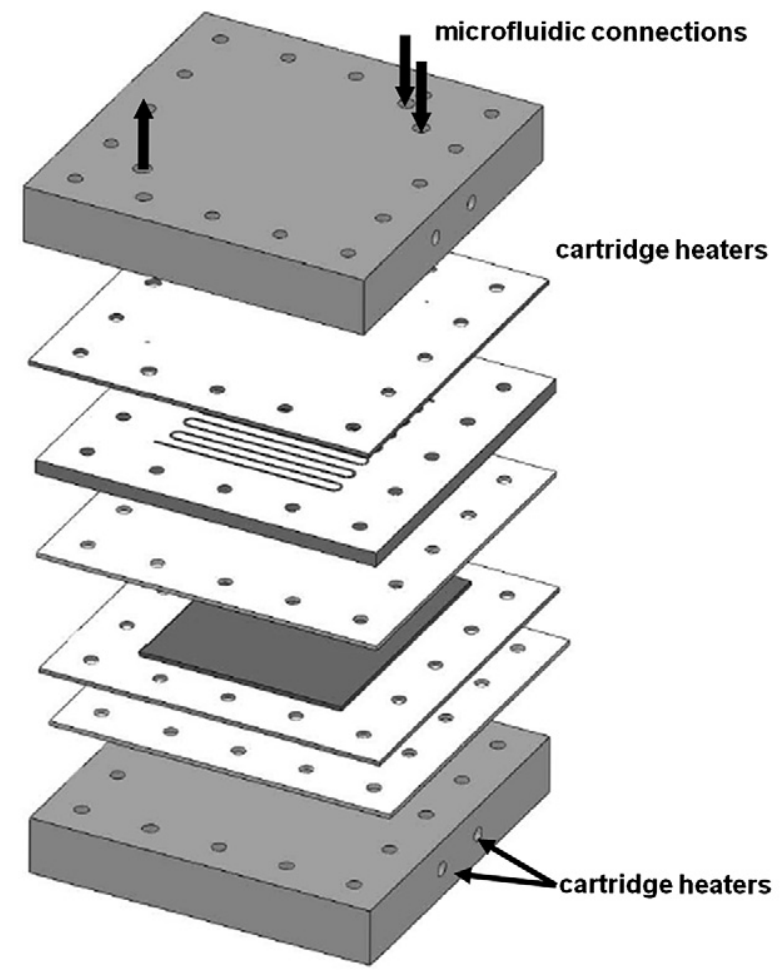

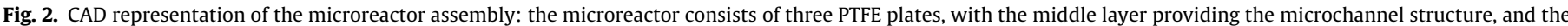

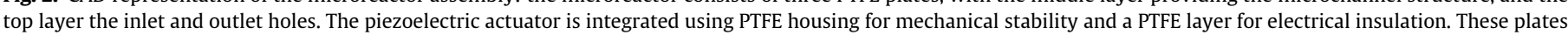

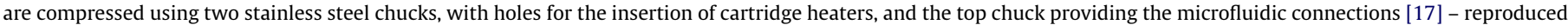
by permission of The Royal Society of Chemistry.

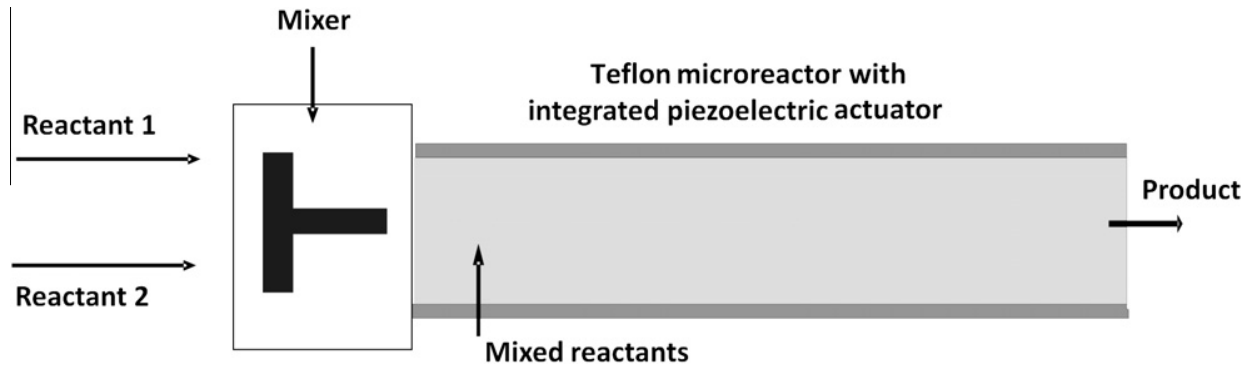

Fig. 3. Schematic representation of the Teflon microreactor with integrated piezoelectric actuator.

Table 1

Operating conditions for the continuous-flow precipitation of HAp.

\begin{tabular}{|c|c|c|c|c|c|c|c|c|}
\hline \multicolumn{2}{|l|}{ Reactants } & \multicolumn{4}{|c|}{ Tubular microreactor } & \multicolumn{3}{|c|}{ Teflon microreactor with integrated piezoelectric actuator } \\
\hline $\begin{array}{l}{\left[\mathrm{Ca}(\mathrm{OH})_{2}\right]} \\
(\mathrm{mM})\end{array}$ & $\begin{array}{l}{\left[\mathrm{H}_{3} \mathrm{PO}_{4}\right]} \\
(\mathrm{mM})\end{array}$ & $\begin{array}{l}\text { Liquid flow rate } \\
\text { (mL/min) }\end{array}$ & $\begin{array}{l}\text { Gas flow rate } \\
\text { (standard } \mathrm{mL} / \mathrm{min} \text { ) }\end{array}$ & $\begin{array}{l}\text { Liquid residence } \\
\text { time } \tau \text { (min) }\end{array}$ & $\begin{array}{l}\text { Ultrasound frequency } \\
\text { and power input }\end{array}$ & $\begin{array}{l}\text { Liquid flow rate } \\
\text { (mL/min) }\end{array}$ & $\begin{array}{l}\text { Liquid residence } \\
\text { time } \tau(\min )\end{array}$ & $\begin{array}{l}\text { Ultrasound frequency } \\
\text { and power input }\end{array}$ \\
\hline 19.3 & 14.5 & $\begin{array}{l}2.0 \\
2.0 \\
2.0\end{array}$ & $\begin{array}{l}- \\
1.2 \\
2.0\end{array}$ & $\begin{array}{l}0.30 \\
0.19 \\
0.15\end{array}$ & $40 \mathrm{kHz}$ and $4-8 \mathrm{~W}$ & 3.3 & 0.30 & $50 \mathrm{kHz}$ and $30 \mathrm{~W}$ \\
\hline
\end{tabular}

of the tubular microreactor, the emitted ultrasonic waves first need to cross the liquid inside the ultrasonic bath (e.g. water) before reaching the microreactor. Therefore, ultrasonication intensity inside the microreactor is lower than expected. In the Teflon microreactor, the acoustic waveform is directly transmitted to the reactor, being thus energetically more efficient and further allowing for a precise control of the operating frequency [17]. Moreover, it should be noted that the precipitation reaction of HAp is exothermic, which also could explain the observed increase in the temperature (Table 2). Thereby, the factors mentioned above may contribute to the temperature increase. Although the temperature variation may influence the characteristics of the final product $[24,25]$, no significant differences in the studied parameters are expected given the small differences observed in the temperature increase (between 0.7 and $3.7^{\circ} \mathrm{C}$ ).

\subsection{Phase identification}

Fig. 4 displays XRD patterns of the products obtained in different systems (Tubular-SPF, Tubular-GLF 1, Tubular-GLF 2 and Tef- 
Table 2

Parameters measured during continuous-flow precipitation of HAp.

\begin{tabular}{|c|c|c|c|c|c|c|c|}
\hline & Sample & Flow type & $\begin{array}{l}\text { Liquid residence } \\
\text { time } \tau \text { (min) }\end{array}$ & $\mathrm{pH}$ (average) & $\begin{array}{l}\text { Precipitate } \\
(\mathrm{mg} / \mathrm{mL})\end{array}$ & $\begin{array}{l}\text { Initial } T \\
\left({ }^{\circ} \mathrm{C}\right)\end{array}$ & $\begin{array}{l}\text { Final } \mathrm{T} \\
\left({ }^{\circ} \mathrm{C}\right)\end{array}$ \\
\hline \multirow{3}{*}{ Tubular microreactor } & Tubular-SPF & Single-phase flow & 0.30 & $7.24 \pm 0.12$ & $1.13 \pm 0.09$ & & 38.0 \\
\hline & Tubular-GLF 1 & Gas-liquid flow & 0.19 & $7.25 \pm 0.35$ & $1.20 \pm 0.10$ & 37.0 & 37.7 \\
\hline & Tubular-GLF 2 & Gas-liquid flow & 0.15 & $7.04 \pm 0.21$ & $1.22 \pm 0.10$ & & 37.0 \\
\hline $\begin{array}{l}\text { Teflon microreactor with integrated } \\
\text { piezoelectric actuator }\end{array}$ & Teflon-SPF & Single-phase flow & 0.30 & $7.23 \pm 0.20$ & $1.39 \pm 0.12$ & 38.3 & 42.0 \\
\hline Stirred tank & Batch & Batch & 330 & $6.90^{\mathrm{a}}$ & $0.91 \pm 0.02$ & 36.7 & 37.9 \\
\hline
\end{tabular}

${ }^{\mathrm{a}} \mathrm{pH}$ value corresponds to the final value.

lon-SPF) and for a commercial HAp. XRD patterns were compared to a reference pattern (JCPDS 00-009-0432), indicating that the product formed is single-phased HAp for all the experimental conditions studied. XRD patterns of the particles obtained possess broader peaks than the commercial HAp, showing thus lower crystallinity. Peaks obtained at $28^{\circ} 2 \theta$ and $40.5^{\circ} 2 \theta$ are sharp and possess high intensity, which is characteristic of high crystallinity and large grain size. These peaks are assigned to potassium chloride and are mainly observed in samples Tubular-SPF, Tubular-GLF 1 and Tubular-GLF 2 patterns. This may be explained by the occlusion of $\mathrm{KCl}$. Indeed, part of the mother liquor could have been trapped between the aggregates, and the $\mathrm{KCl}$ contained in the mother liquor crystallized at the drying step.

Based on peaks identified (Fig. 5 and Table 3), the synthesis products have a typical apatite structure. Presence of adsorbed water in the products formed is also verified, since a broad band from approximately $3700-3000 \mathrm{~cm}^{-1}$ and a peak at $1643 \mathrm{~cm}^{-1}$ (bending mode, $v_{2}$ ) are observed. This may be justified by the low drying temperature $\left(80^{\circ} \mathrm{C}\right)$ and the absence of a ripening (aging) treatment $[22,26,27]$. As to the functional groups of HAp, characteristic bands of the phosphate group, $\mathrm{PO}_{4}^{3-}$, are exhibited in all the spectra, although in some cases (Tubular-SPF) broad and unresolved. The peak assigned to the stretching mode, $v_{S}$, (around $3571 \mathrm{~cm}^{-1}$ ) of the hydroxyl group, $\mathrm{OH}^{-}$, is weak in all the spectra, and the peak assigned to its vibrational mode, $v_{L}$, (around $630 \mathrm{~cm}^{-1}$ ) is only visible in the spectrum of the commercial HAp. This may be due to an overlap with the broad peak of the adsorbed water [28]. Further, it is common to find substitution in the apatite structure, namely involving carbonate, $\mathrm{CO}_{3}^{2-}$, and hydrogen phosphate, $\mathrm{HPO}_{4}^{2-}$. From literature, peaks located at 870 and $875 \mathrm{~cm}^{-1}$ can be attributed to the vibrational frequencies of carbonate ions, which can indicate the formation of carbonated $\mathrm{HAp}$ [29]. Regarding the peaks associated to the $\mathrm{HPO}_{4}^{2-}$ group, they are observed in all the spectra, which can be associated with the formation of calcium-deficient HAp [30]. Therefore, HAp formed seems to present characteristics similar to biological apatites, as they generally are considered calcium-deficient carbonated apatites [15]. Information on the crystallinity is also available by IR spectroscopy. It can be seen that the product obtained in the Teflon microreactor (Teflon-SPF) is more crystalline when compared to the others precipitates, especially when observing the phosphate bands around $1000 \mathrm{~cm}^{-1}$, which are broad and unresolved in the other samples, indicating poor crystallinity [31]. Moreover, the broad band corresponding to the adsorbed water (3700$3000 \mathrm{~cm}^{-1}$ ) is much smaller than the other spectra.

The noise observed in almost all the spectra and especially in the commercial HAp spectrum $\left(1800-1400 \mathrm{~cm}^{-1}\right)$ is due to water vapor.

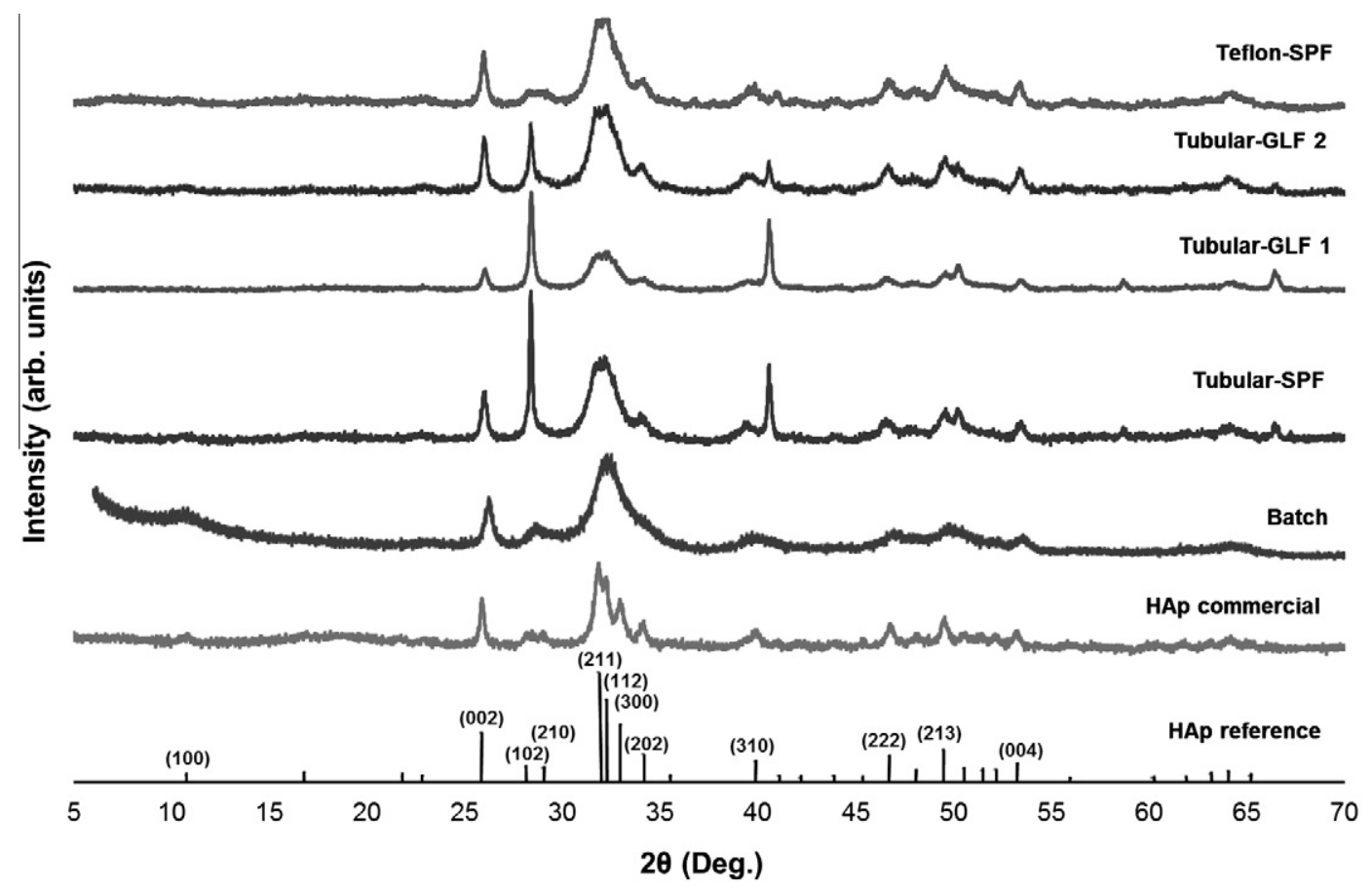

Fig. 4. XRD patterns of the HAp particles produced in different reactors. 


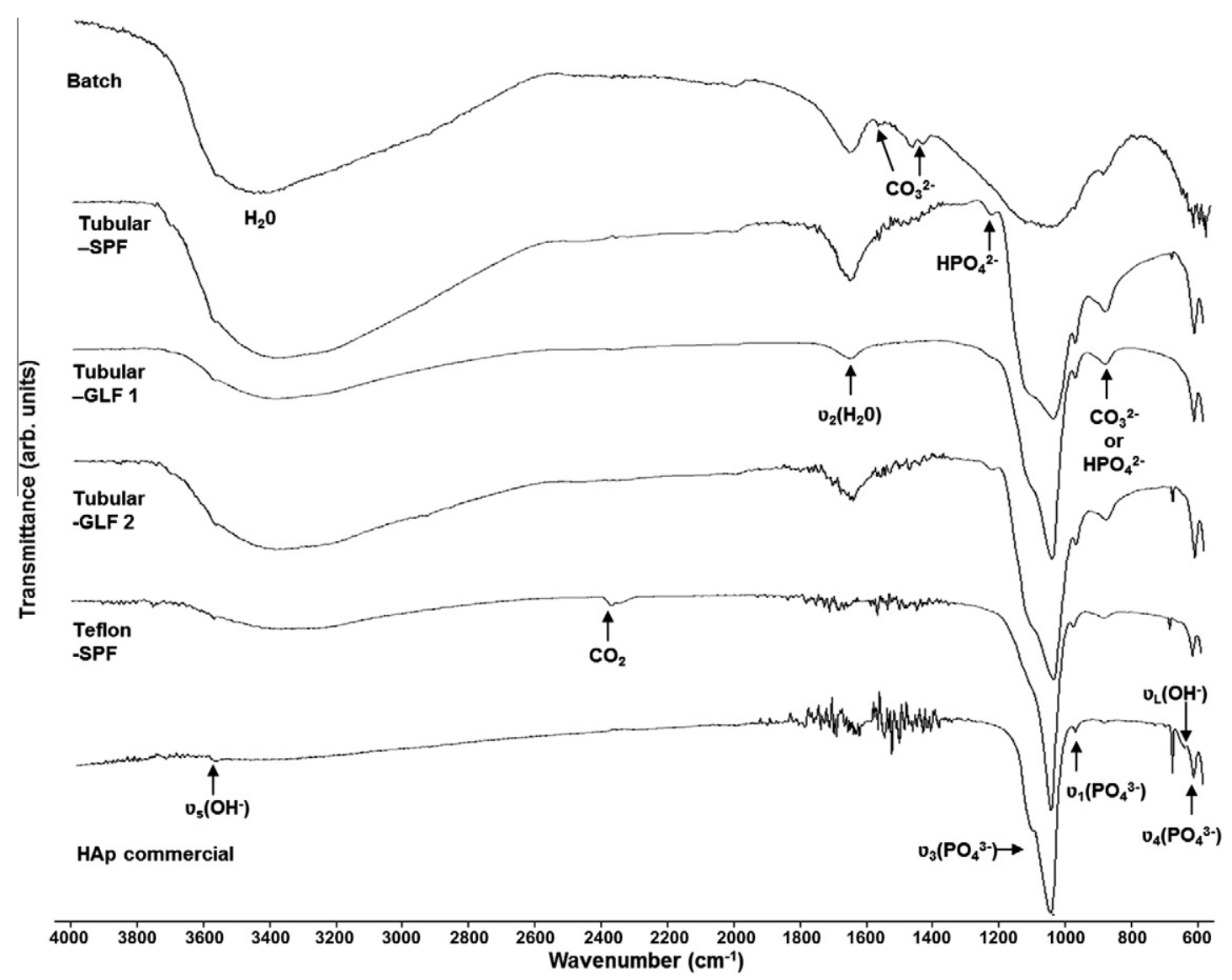

Fig. 5. FTIR spectra of the HAp particles produced in different reactors.

Table 3

FTIR bands of HAp powders.

\begin{tabular}{|c|c|c|c|c|c|c|}
\hline \multirow[t]{2}{*}{ Groups } & \multicolumn{6}{|c|}{ Wavenumber $\left(\mathrm{cm}^{-1}\right)$} \\
\hline & HAp commercial & Tubular-SPF & Tubular-GLF 1 & Tubular-GLF 2 & Teflon-SPF & Batch \\
\hline$v_{S}\left(\mathrm{OH}^{-}\right) ; v_{L}\left(\mathrm{OH}^{-}\right)$ & $3571 ; 630$ & 3565 & 3566 & 3565 & 3566 & 3570 \\
\hline $\begin{array}{l}v_{1}\left(\mathrm{PO}_{4}^{3-}\right) ; v_{3}\left(\mathrm{PO}_{4}^{3}\right) ; v_{4}\left(\mathrm{PO}_{4}^{3-}\right) \\
v_{1}\left(\mathrm{CO}_{3}^{2-}\right) ; v_{3} \text { or } v_{4}\left(\mathrm{CO}_{3}^{2-}\right)\end{array}$ & $962 ; 1037 ; 603$ & $961 ; 1027 ; 601$ & $962 ; 1031 ; 602$ & $961 ; 1029 ; 602$ & $962 ; 1029 ; 600$ & $\begin{array}{l}\text { Approximately at } 961^{\text {a }} ; 1029 ; 600 \\
1454 ; 1428\end{array}$ \\
\hline$v_{2}\left(\mathrm{CO}_{3}^{2-}\right) ; \mathrm{HPO}_{4}^{2-}$ & & 871 & 872 & 872 & 871 & 874 \\
\hline $\mathrm{HPO}_{4}^{2-}$ & & 1215 & & 1215 & & \\
\hline $\mathrm{HOH}$ & Around $1643^{\mathrm{b}}$ & $3000-3700 ; 1643$ & & & & \\
\hline
\end{tabular}

a Broadening of the peaks assigned to $\mathrm{PO}_{4}^{3-}$, thus leading to difficulties in peak identification.

b Peaks assigned to $\mathrm{HOH}$ in the commercial HAp are due to the water present in the atmosphere.

\subsection{Particle morphology, size and size distribution}

It was chosen to present particle size distribution results as both volume and number distributions, allowing thus to detect the presence of aggregates and to study the size of the majority of the particles, respectively. According to the volume distribution (Fig. 6a and Table 4), there are significant differences in particles size distribution, depending on the reactor used. For the study conducted in the tubular microreactor, results show the formation of aggregates with a mean particle diameter $\left(d_{50}\right)$ of $38.30 \mu \mathrm{m}$ in single-phase flow, while for the gas-liquid flow experiments, Fig. 6a shows a bimodal population with micrometric-size aggregates and particles of about $100-200 \mathrm{~nm}$. Using gas to create a segmented flow results in the formation of small reacting entities separated from each other by gas bubbles, which reduces particle-to particle interactions, and thus the formation of aggregates [17]. Nevertheless, some aggregation occurs, possibly due to the small size of the particles and their amorphous state. The particles formed possess a high surface area to volume ratio, resulting in a high surface tension, which can be lowered by particles adhering to one another [12]. Moreover, the $\mathrm{pH}$ conditions could favor the formation of aggregates, since the isoelectric point (IEP) of HAp varies between 4 and 6 [32], which is close to the final $\mathrm{pH}$ of the suspension (Table 2). Regarding the product formed in the Teflon microreactor, it is mainly constituted by particles with sizes between 100 and $200 \mathrm{~nm}$ (Fig. 6a). Larger aggregates with sizes around $100 \mu \mathrm{m}$, not observed in the tubular microreactor, are also present. This could be explained by the fact that smaller particles were formed in the Teflon reactor and have thus higher tendency to aggregate. Besides, by reducing channel width and increasing 

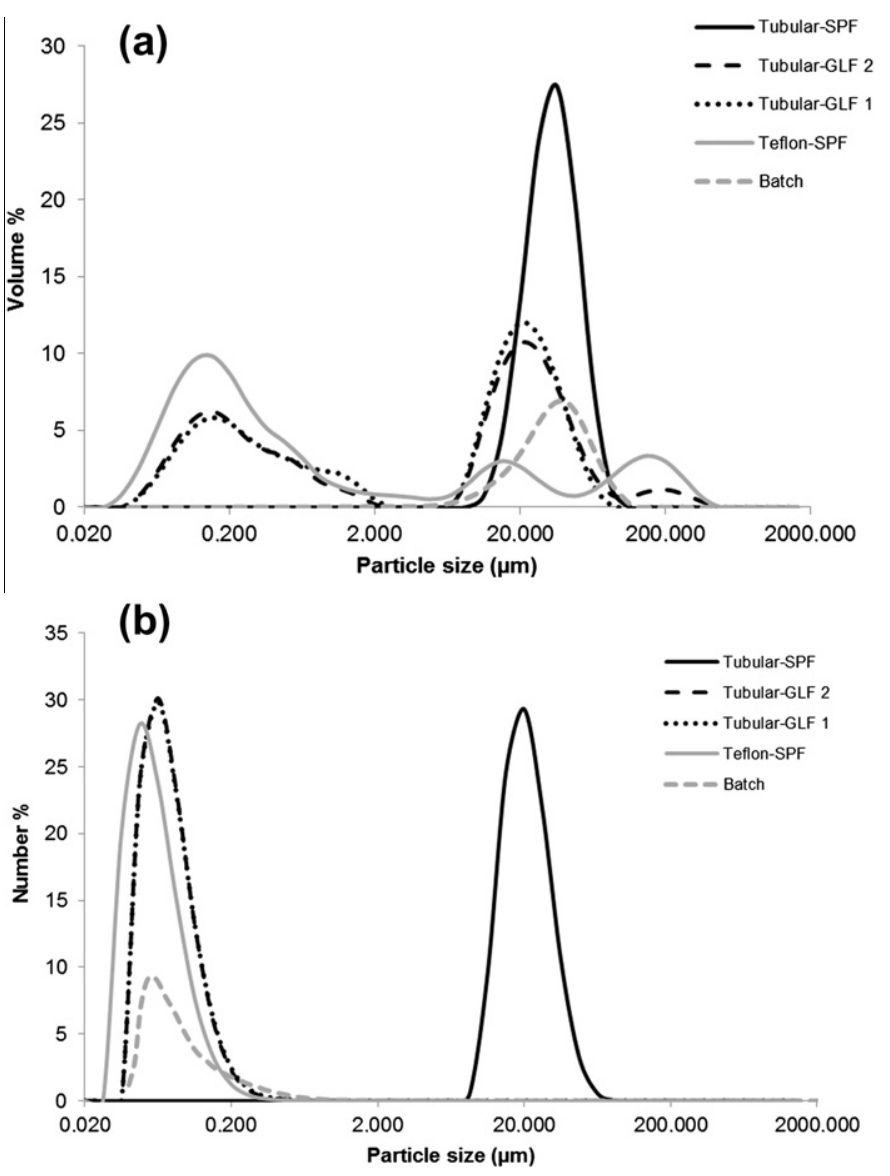

Fig. 6. (a) Size distribution in volume of the HAp particles produced in different reactors and (b) size distribution in number of the HAp particles produced in different reactors.

Table 4

Parameters of the particle size distribution of HAp powders produced in the microreactors. $d_{10}: 10 \%$ of the particles are smaller than this value, $d_{50}$ : median particle diameter; $d_{90}$ : $90 \%$ of the particles are smaller than this value.

\begin{tabular}{|c|c|c|c|}
\hline & \multicolumn{3}{|c|}{ Particle size $(\mu \mathrm{m})$} \\
\hline & $d_{10}$ & $d_{50}$ & $d_{90}$ \\
\hline \multicolumn{4}{|c|}{ Volume distribution } \\
\hline Tubular-SPF & 22.59 & 38.30 & 62.70 \\
\hline Tubular-GLF 1 & 0.14 & 13.90 & 40.94 \\
\hline Tubular-GLF 2 & 0.13 & 14.88 & 52.33 \\
\hline Teflon-SPF & 0.09 & 0.33 & 136.67 \\
\hline \multicolumn{4}{|c|}{ Number distribution } \\
\hline Tubular-SPF & 11.25 & 17.64 & 30.42 \\
\hline Tubular-GLF 1 & 0.04 & 0.06 & 0.13 \\
\hline Tubular-GLF 2 & 0.04 & 0.06 & 0.11 \\
\hline Teflon-SPF & 0.03 & 0.05 & 0.10 \\
\hline
\end{tabular}

the ultrasound power input, the probability of particles to collide and thereby to aggregate is higher [12]. Therefore, volume-based results show the formation of aggregates for the all experimental conditions studied. However, the particle size distribution in number (obtained from the conversion of the particle size distribution in volume) shows that most of the as-prepared particles are at the nanometer size (Fig. $6 \mathrm{~b}$ and Table 4). Indeed, the median particle diameter $\left(d_{50}\right)$ is around $60-50 \mathrm{~nm}$ for almost all the powders, except for the sample Tubular-SPF, which is characterized by micrometric-size particles. (a)

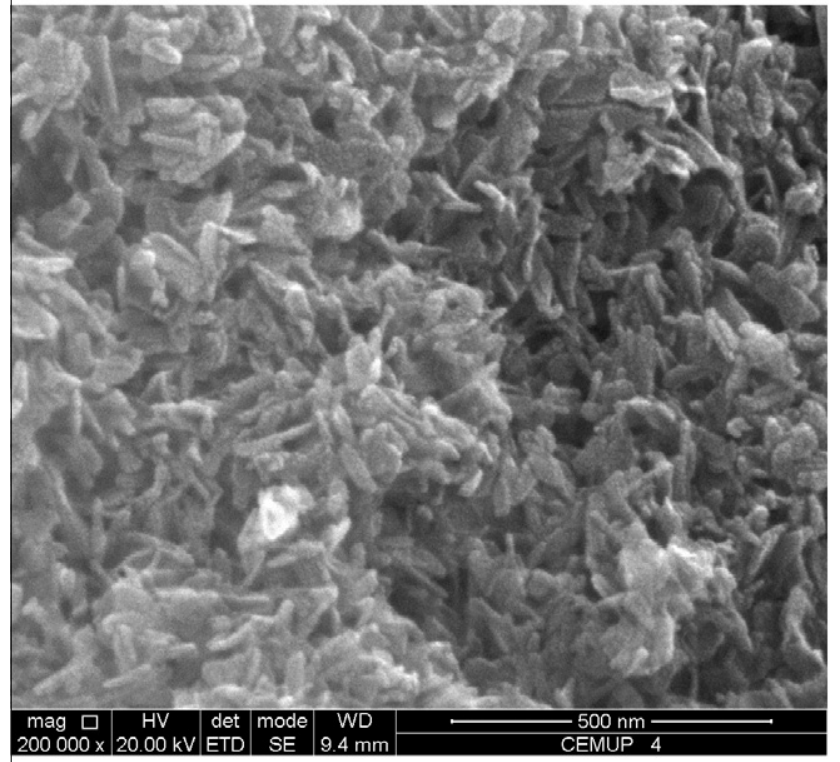

(b)

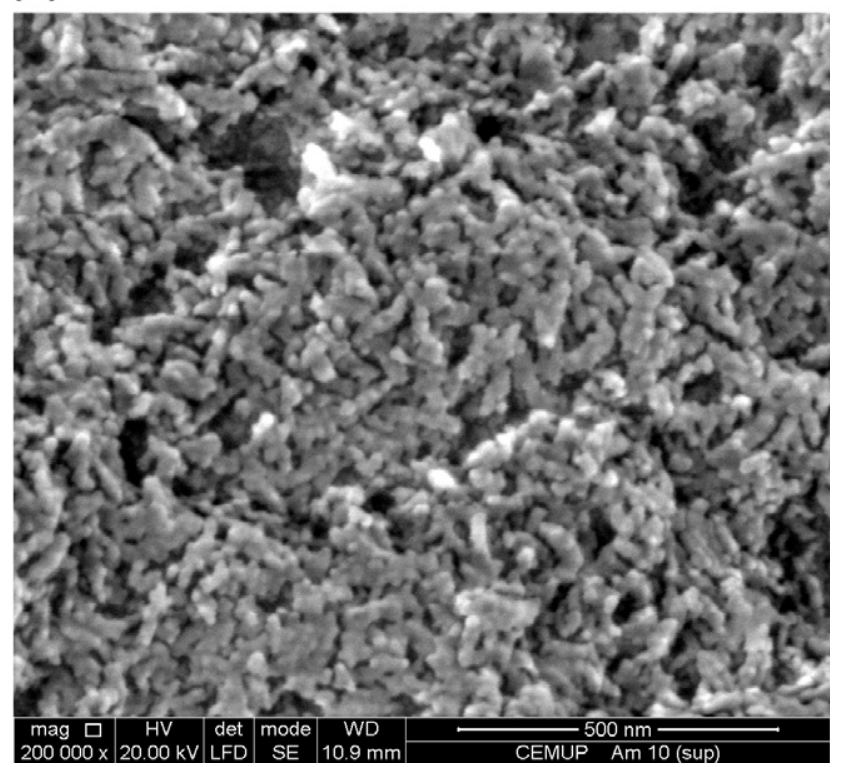

Fig. 7. (a) SEM image of the HAp particles produced in the microreactors and (b) SEM image of the HAp particles produced in a stirred tank batch reactor.

SEM images (Fig. 7a) show aggregated nano-size particles for all the operation conditions studied. The microstructure of the HAp particles was also observed by TEM analysis (Fig. 8). Primary particles seem uniform in size and shape, presenting less than $100 \mathrm{~nm}$ in length and around $20 \mathrm{~nm}$ in width, and a rod-like shape.

The as-prepared particles present therefore interesting characteristics for biomedical applications. Actually, nanocrystalline HAp powders exhibit greater surface area [16] when compared to microscale HAp. Moreover, it is desirable that the HAp for use in implants be bioresorbable so that it can be replaced, over a period of time, with regenerated bone upon implantation. In this context, nanoparticles of HAp have shown higher rates of bioresorbability than micrometric HAp, and close to biological apatite [33]. Further, the resorbability of HAp can be developed with improving its crystallinity degree similar to biological HAp (60-70\%) [34]. 

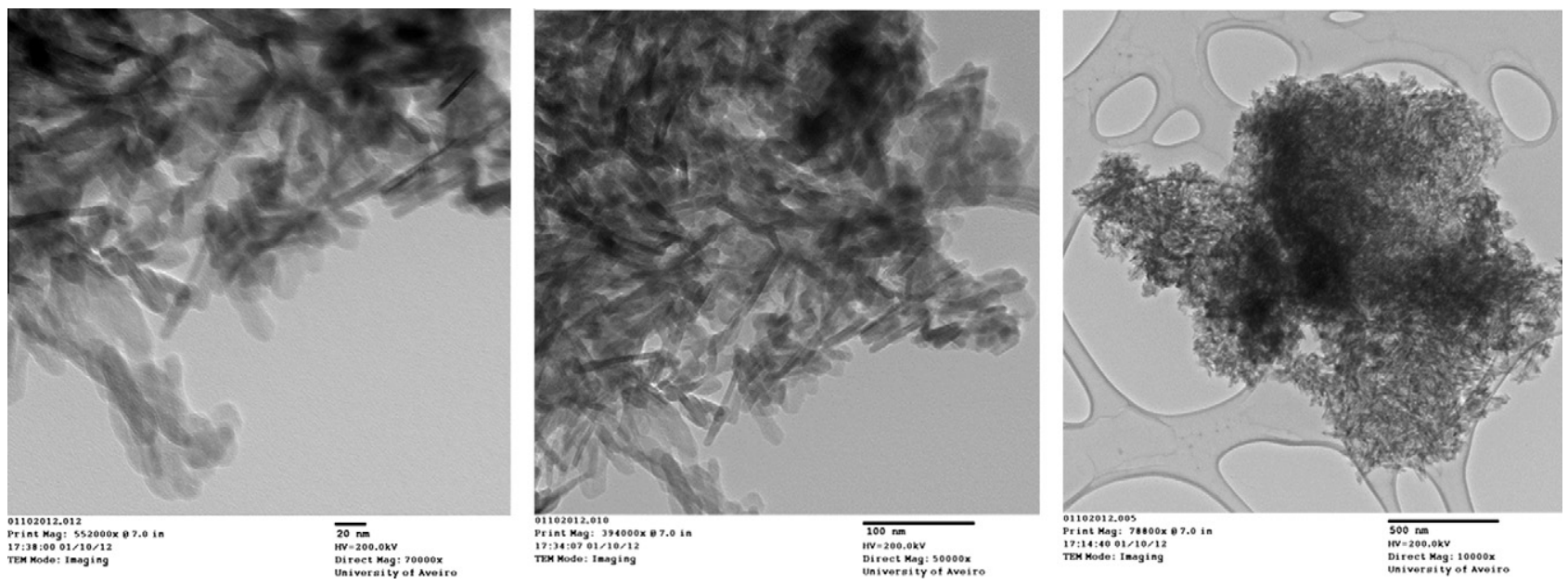

Fig. 8. TEM images of the HAp particles produced in the microreactors.

\subsection{Comparison of HAp particles prepared in a stirred tank batch} reactor and in the microreactors

XRD and FTIR results (Figs. 4 and 5) show some differences between HAp particles formed in the microsystems and in a stirred tank batch reactor [19]. Particles obtained in batch appear to be less crystalline than the particles formed in the microreactors, since their XRD pattern and FTIR spectrum exhibit broader peaks (Figs. 4 and 5). Furthermore, bands attributed to carbonate ions at approximately 1454, 1428 and $878 \mathrm{~cm}^{-1}$ are clearly observed in the spectrum of the particles obtained in batch (Fig. 5), indicating the formation of carbonated HAp of B-type [29]. As referred in Castro et al. (2012), presence of carbonate ions can be explained by the absorption of $\mathrm{CO}_{2}$ from air, once the reaction system was open to air. On the other hand, carbonate bands at approximately 1454 and $1428 \mathrm{~cm}^{-1}$ are not exhibited in the spectra of the HAp powders formed in the microsystems. In this case, systems were not open to air and carbonate ions could only come from the water used in the preparation of the reagents. Regarding particle size distribution one can verify that particle aggregation was significantly reduced in the segmented-flow tubular microreactor and especially in the Teflon microreactor (Fig. 6a). Further, smaller primary particles were obtained in the Teflon microreactor (Fig. 6b). Regarding morphology and size of the HAp particles, in all the reactors rod-like shape nanoparticles were formed (Figs. 7a, b and 8).

\section{Conclusion}

Continuous-flow precipitation of HAp was studied in two ultrasonic microreactors, a tubular microreactor immersed in an ultrasonic bath and a Teflon microreactor with integrated piezoelectric actuator. The as-prepared particles, irrespective of the system used, consisted of nano-size calcium-deficient carbonated HAp particles, thus approaching biological apatites. Moreover, particles were obtained under near-physiological conditions of $\mathrm{pH}$ and temperature, making them promising compounds for bone substitution application.

Several configurations were tested in the tubular microreactor (single-phase flow and gas-liquid flow), and segmentation of the flow was successful in reducing particle aggregation. Control of aggregation was however best achieved in the Teflon microreactor, primarily due to the higher intensity of the ultrasound.

Synthesis products were also compared to the product obtained in a stirred tank batch reactor. The HAp particles formed have proved to be more crystalline and less carbonate contaminated than the HAp particles produced in the batch reactor. Moreover, microreactors used yielded HAp particles in a very short time and at a constant $\mathrm{pH}$. Finally, particle aggregation and primary particle size were significantly reduced in the segmented-flow tubular microreactor and especially in the Teflon microreactor.

\section{Acknowledgments}

This work was supported by the Portuguese Foundation for Science and Technology (SFRH/BD/42992/2008) through the MIT-Portugal Program, Bioengineering Systems Focus Area. The authors are thankful to Dr. Speakman for his help with the X-ray measurements and with the interpretation of the results. S.K. acknowledges funding from the Swiss National Science Foundation (SNF).

\section{References}

[1] S. Bose, S.K. Saha, Synthesis and characterization of hydroxyapatite nanopowders by emulsion technique, Chem. Mater. 15 (2003) 4464-4469.

[2] Q.-A. Wang, J.-X. Wang, M. Li, L. Shao, J.-F. Chen, L. Gu, Y.-T. An, Large-scale preparation of barium sulphate nanoparticles in a high-throughput tube-intube microchannel reactor, Chem. Eng. J. 149 (2009) 473-478.

[3] D. Jeevarathinam, A.K. Gupta, B. Pitchumani, R. Mohan, Effect of gas and liquid flowrates on the size distribution of barium sulfate nanoparticles precipitated in a two phase flow capillary microreactor, Chem. Eng. J. 173 (2011) 607-611.

[4] L.-H. Hung, A.P. Lee, Microfluidic devices for the synthesis of nanoparticles and biomaterials, J. Med. Biol. Eng. 27 (2007).

[5] J. Leng, J.-B. Salmon, Microfluidic crystallization, Lab Chip 9 (2009) 24-34.

[6] Y. Song, J. Hormes, C.S.S.R. Kumar, Microfluidic synthesis of nanomaterials, Small 4 (2008) 698-711.

[7] S. Marre, K.F. Jensen, Synthesis of micro and nanostructures in microfluidic systems, Chem. Soc. Rev. 39 (2010) 1183-1202.

[8] C.-X. Zhao, L. He, S.Z. Qiao, A.P.J. Middelberg, Nanoparticle synthesis in microreactors, Chem. Eng. Sci. 66 (2011) 1463-1479.

[9] S.L. Poe, M.A. Cummings, M.P. Haaf, D.T. McQuade, Solving the clogging problem: precipitate-forming reactions in flow, Angew. Chem. Int. Ed. 45 (2006) 1544-1548.

[10] A. Gunther, K.F. Jensen, Multiphase microfluidics: from flow characteristics to chemical and materials synthesis, Lab Chip 6 (2006) 1487-1503.

[11] S.A. Khan, K.F. Jensen, Microfluidic synthesis of titania shells on colloidal silica Adv. Mater. 19 (2007) 2556-2560.

[12] M.D. Luque de Castro, F. Priego-Capote, Ultrasound-assisted crystallization (sonocrystallization), Ultrason. Sonochem. 14 (2007) 717-724.

[13] M.P. Ferraz, F.J. Monteiro, C.M. Manuel, Hydroxyapatite nanoparticles: a review of preparation methodologies, J. Appl. Biomater. Biomech. 2 (2004) 7480.

[14] Q. He, Z. Huang, Y. Liu, W. Chen, T. Xu, Template-directed one-step synthesis of flowerlike porous carbonated hydroxyapatite spheres, Mater. Lett. 61 (2007) 141-143.

[15] P.N. Kumta, C. Sfeir, D.-H. Lee, D. Olton, D. Choi, Nanostructured calcium phosphates for biomedical applications: novel synthesis and characterization, Acta Biomater. 1 (2005) 65-83. 
[16] I. Mobasherpour, M.S. Heshajin, A. Kazemzadeh, M. Zakeri, Synthesis of nanocrystalline hydroxyapatite by using precipitation method, J. Alloys Compd. 430 (2007) 330-333.

[17] S. Kuhn, T. Noel, L. Gu, P.L. Heider, K.F. Jensen, A Teflon microreactor with integrated piezoelectric actuator to handle solid forming reactions, Lab Chip 11 (2011) 2488-2492.

[18] K. Johannsen, S. Rademacher, Modelling the kinetics of calcium hydroxide dissolution in water, Cryst. Res. Technol. 27 (1999) 72-78

[19] F. Castro, A. Ferreira, F. Rocha, A. Vicente, J. António Teixeira, Characterization of intermediate stages in the precipitation of hydroxyapatite at $37^{\circ} \mathrm{C}$, Chem. Eng. Sci.

[20] L. Bernard, M. Freche, J.L. Lacout, B. Biscans, Modeling of the dissolution of calcium hydroxyde in the preparation of hydroxyapatite by neutralization, Chem. Eng. Sci. 55 (2000) 5683-5692.

[21] J.C. Elliot, Structure and Chemistry of the Apatites and Other Calcium Orthophosphates, Elsevier, Amsterdam, 1994.

[22] S. Koutsopoulos, Synthesis and characterization of hydroxyapatite crystals: a review study on the analytical methods, J. Biomed. Mater. Res. 62 (2002) 600612.

[23] M. Pankaj, M. Ashokkumar, Theoretical and Experimental Sonochemistry Involving Inorganic Systems, Springer, New York, 2010.

[24] M.A. Martins, C. Santos, M.M. Almeida, M.E.V. Costa, Hydroxyapatite microand nanoparticles: nucleation and growth mechanisms in the presence of citrate species, J. Colloid Interface Sci. 318 (2008) 210-216.

[25] P.G. Koutsoukos, Current knowledge of calcium phosphate chemistry and in particular solid surface-water interface interactions, in: Proceedings of the
Second International Conference on Phosphorus Recovery for Recycling from Sewage and Animal Wastes, Institute of Chemical Engineering and High Temperature Chemical Processes, Univ. of Patras, 2000, pp. 12-14.

[26] A. Osaka, Y. Miura, K. Takeuchi, M. Asada, K. Takahashi, Calcium apatite prepared from calcium hydroxide and orthophosphoric acid, J. Mater. Sci. Mater. Med. 2 (1991) 51-55.

[27] W. Zhou, M. Wang, W. Cheung, B. Guo, D. Jia, Synthesis of carbonated hydroxyapatite nanospheres through nanoemulsion, J. Mater. Sci. - Mater. Med. 19 (2008) 103-110.

[28] M.-G. Ma, J.-F. Zhu, Solvothermal synthesis and characterization of hierarchically nanostructured hydroxyapatite hollow spheres, Eur. J. Inorg. Chem. 2009 (2009) 5522-5526.

[29] E. Landi, G. Celotti, G. Logroscino, A. Tampieri, Carbonated hydroxyapatite as bone substitute, J. Eur. Ceram. Soc. 23 (2003) 2931-2937.

[30] S. Meejoo, W. Maneeprakorn, P. Winotai, Phase and thermal stability of nanocrystalline hydroxyapatite prepared via microwave heating, Thermochim. Acta 447 (2006) 115-120.

[31] D. Tadic, F. Peters, M. Epple, Continuous synthesis of amorphous carbonated apatites, Biomaterials 23 (2002) 2553-2559.

[32] E. Bouyer, F. Gitzhofer, M.I. Boulos, Morphological study of hydroxyapatite nanocrystal suspension, J. Mater. Sci. - Mater. Med. 11 (2000) 523-531.

[33] R. Murugan, S. Ramakrishna, Aqueous mediated synthesis of bioresorbable nanocrystalline hydroxyapatite, J. Cryst. Growth 274 (2005) 209-213.

[34] M.H. Fathi, A. Hanifi, V. Mortazavi, Preparation and bioactivity evaluation of bone-like hydroxyapatite nanopowder, J. Mater. Process. Technol. 202 (2008) 536-542. 